\title{
Corrosion of Mild Steel with Composite Alkyd Polyaniline- benzoate Coating
}

\author{
Ayad A. Salem, Branimir N. Grgur* \\ Faculty of Technology and Metallurgy, University of Belgrade, Karnegijeva 4, 11020 Belgrade, Serbia \\ *E-mail: BNGrgur@tmf.bg.ac.rs
}

doi: $10.20964 / 2017.09 .57$

Received: 29 June 2017 / Accepted: 19 July 2017 / Published: 13 August 2017

The synthesis of the polyaniline in the emeraldine salt form by the procedure suggested by IUPAC is successful preformed. Emeraldine salt form is deprotonated with ammonium hydroxide and reprotonated with benzoic acid. Using the UV-visible spectroscopy the doping degree of 0.25 is estimated. The corrosion performances of the base coating and composite coating with 5 wt.\% of polyaniline benzoate on mild steel are investigated by the means of linear polarization measurements and results are compared with in site determined iron concentrations in the corrosive media using ASTM 1,10-phenanthroline method and the corrosion current density is recalculated. Excellent agreement between these two methods is achieved. It is shown that composite containing polyaniline, offers an order of magnitude better corrosion protection than base coating, and more than three order of magnitude than pure mild steel.

Keywords: Conducting polymers; Reprotonation; Polarization resistance; Corrosion current

\section{$\underline{\text { FULL TEXT }}$}

(C) 2017 The Authors. Published by ESG (www.electrochemsci.org). This article is an open access article distributed under the terms and conditions of the Creative Commons Attribution license (http://creativecommons.org/licenses/by/4.0/). 